\title{
Isolated vocal tremor as a focal phenotype of essential tremor: a retrospective case review
}

\author{
Amar Patel ${ }^{*}$ and Steven J Frucht
}

\begin{abstract}
Background: Essential tremor (ET) is a common condition associated with significant physical and psychosocial disability. "Classic" ET is a clinical syndrome of action tremor in the upper limbs and less commonly the head, jaw, voice, trunk, or lower limbs. Current diagnostic criteria for ET exclude isolated vocal tremor (IVT). Failure to recognize IVT as a form of ET may contribute to misdiagnosis and missed opportunities for treatment.

Methods: We conducted a retrospective review of cases referred for voice disturbance. Patients with a primary diagnosis of vocal tremor were included while those with a diagnosis of spasmodic dysphonia where excluded.

Results: 19 cases of vocal tremor were identified, of which 17 patients (89\%) were female. The average age of vocal symptom onset was 64 (SD 8.0) and patients had been symptomatic an average of 6 years (SD 4) at their initial visit. 8 patients had IVT while 11 also had evidence of subtle head or limb tremor. 8 patients (42\%) had a family history of ET, with vocal tremor specifically identified in 5 of those cases (26\%). 11 patients (58\%) noted transient tremor improvement after alcohol consumption. Primidone and propranolol were the most common medications prescribed to these patients prior to consultation. 7 patients were given a trial of $1 \mathrm{gm}$ of sodium oxybate in the office as part of a clinical trial, with at least mild improvement in vocal tremor noted by qualitative assessment.

Conclusions: ET may present as vocal tremor with little or no associated limb tremor. It may be a more common manifestation of ET in women. A family history of tremor and improvement in tremor after consuming alcohol can often be elicited on history. We propose that IVT may be part of the spectrum of ET.
\end{abstract}

Keywords: Vocal tremor, Isolated vocal tremor, Essential tremor, Pharyngeal tremor, Sodium oxybate

\section{Background}

Essential tremor (ET) is the most common pathological cause of tremor, defined as a rhythmic, oscillatory movement of a body part about an axis. ET is the most common movement disorder in the general population and of those presenting for neurological evaluation [1]. Many cases of ET are familial, with anywhere from $17 \%$ to $100 \%$ cited in various studies, and inherited most likely in an autosomal dominant fashion with variable penetrance $[2,3]$. The tremor of ET occurs during voluntary movement, posture and action [4]. ET has been defined by the Movement Disorder Society Consensus Statement on Tremor as a "bilateral, largely symmetric postural or kinetic tremor involving hands and forearms that is visible and persistent" [5]. These criteria were based on

\footnotetext{
* Correspondence: amar.patel@mountsinai.org
Department of Neurology, Icahn School of Medicine at Mount Sinai, 5 E 98th

* Correspondence: amar.patel@mountsinai.org
Department of Neurology, Icahn School of Medicine at Mount Sinai, 5 E 98th Street, New York, NY 10029, USA
}

(C) 2015 Patel and Frucht; licensee BioMed Central. This is an Open Access article distributed under the terms of the Creative Commons Attribution License (http://creativecommons.org/licenses/by/4.0), which permits unrestricted use, distribution, and reproduction in any medium, provided the original work is properly credited. The Creative Commons Public Domain Dedication waiver (http://creativecommons.org/publicdomain/zero/1.0/) applies to the data made available in this article, unless otherwise stated.
Tremor Investigation Group guidelines which also included duration of illness as a major criterion [6]. Other causes of tremor, e.g. dystonia, must be excluded, and although traditionally vocal tremor is recognized as a feature of ET in anywhere from 10 to $25 \%$ of cases, isolated vocal tremor (IVT), defined as tremor of the voice in the absence of other observable tremor, does not meet current criteria for ET [7]. Voice tremor has thus classically been considered a secondary feature of ET which does not occur without upper limb tremor.

Here we describe a series of cases in which tremor of the phonatory apparatus is the sole or predominant manifestation of ET. We also compare the current series to previously described essential voice tremor populations. We propose that the phenomenologic characteristics of isolated vocal tremor (IVT) are consistent with its inclusion as a focal form of ET; and where both vocal and limb 
tremor occur, the former need not be a secondary feature of the latter, but rather the primary concern of the patient.

\section{Methods}

We conducted a retrospective review of the medical records of patients referred to the senior author for voice disturbance over a ten-year period. Patients with a diagnosis of vocal tremor were included, while those with a diagnosis of spasmodic dysphonia where excluded. The study was approved by the Institutional Review Board of Mount Sinai School of Medicine. Written informed consent was obtained for the use of video examinations. A waiver of consent for review of medical records was granted by the IRB.

\section{Results}

19 patients with a primary diagnosis of vocal tremor were evaluated between 2003 and 2013 (Table 1). 17 patients (89\%) were female. The average age of onset of vocal difficulty was 64 (SD 8.0). Patients had been symptomatic an average of 6 years (SD 4) upon their initial consultation. 8 patients (42\%) had a family history of ET, with vocal tremor specifically identified in 5 of those cases (26\%). 11 patients (58\%) noted transient tremor improvement after alcohol consumption; the remaining patients did not drink alcohol. On examination, 17 patients $(89 \%)$ had a visible tremor of the pharyngeal musculature when speaking. Sustained vowel (A and E) phonation most reliably brought out the rhythmic oscillations of voice intensity at a frequency of approximately 4-8 Hz. Supplementary patient videos show this in greater detail for a sample of the patients described in this case series [see Additional file 1: Videos S1 and S2 and Additional file 2: Video S3]. All 9 patients who were referred for or had prior videostroboscopic evaluation of the vocal cords had visual confirmation of vocal tremor. 6 patients (32\%) were noted to have very slight head tremor while 3 patients (16\%) had very mild action tremor of the upper extremities. Two patients had both mild head and limb tremor. Of these 11 patients with vocal tremor plus tremor elsewhere, 4 had videostroboscopic evaluation of the vocal cords that was more consistent with vocal tremor rather than spasmodic dysphonia. Rest tremor of the upper limbs was present in only one patient, and none had signs of rigidity or bradykinesia to support a diagnosis of parkinsonism. No patient had sought medical treatment of their head or limb tremor prior to consultation for their voice tremor. Primidone and propranolol were the most common medications prescribed to these patients prior to consultation. 7 patients were treated with $1 \mathrm{gm}$ of the alcohol analogue sodium oxybate after their consultation as part of a separate IRB-approved clinical trial. All 7 patients were observed to have at least mild improvement in vocal tremor, as noted by a reduction in the amplitude of the tremor without a change in its frequency. Patients were subsequently followed for as little as 6 months and as long as 10 years without the development of dystonia or parkinsonism.

\section{Discussion}

The present case series provides some comparisons and contrasts with previously reported populations of voice tremor (Table 2). In agreement with previous reports is the finding that voice tremor is a condition of the elderly. The largest study population of voice tremor patients included only two cases of voice tremor presenting in the second and third decade of life [8]. This matches the association of another "midline" symptom, head tremor, with older age independent of duration of tremor [9]. Although epidemiological studies of ET find an equal gender distribution [10], voice tremor seems to affect more women, who represent approximately $80 \%$ of the patients identified in the literature. This corresponds with a similar gender bias in head tremor [9], suggesting that older age and female gender are defining characteristics of midline ET symptoms. Given the relatively small number of patients in some of these case series selection bias is possible, and a population-based study of essential voice tremor would be needed to more definitively address the question. Rates of familial voice tremor appear to be similar to those of familial limb tremor, although the heterogeneity of inheritance rates and patterns in the latter make this comparison less useful clinically [2].

A significant proportion of patients in the present case series reported transient tremor improvement after drinking alcohol, at rates similar to other studies of voice tremor. In fact, all alcohol "non-responders" were unaware of their response due to reported abstention from alcohol. This would suggest that an even greater percentage of voice tremor cases would respond if challenged with alcohol and objectively measured. Such a high percentage of voice tremor response to alcohol is in line with reported rates of response of limb tremor in those patients aware of the effect of alcohol on tremor [18]. Given the robust response to alcohol, it is not surprising that all patients treated with sodium oxybate had at least a mild reported improvement in voice tremor. Sodium oxybate is the salt form of $\gamma$-hydroxybutyric acid. Mice deficient in GABA $_{a}$ receptor have an ET-like tremor that improves with ethanol, suggesting a GABAergic mechanism in ET [19]. A previous open-label, single-blinded trial of sodium oxybate with medically refractory ET showed a dose-dependent improvement in tremor ratings [20]. Three of the patients in the current case series who responded to sodium oxybate had previously had no response to primidone and propranolol. Proper diagnosis of voice tremor can thus lead to alternative medication strategies for this often refractory condition. 
Table 1 Case series

\begin{tabular}{|c|c|c|c|c|c|c|c|c|c|c|c|c|}
\hline Case & Gender & $\begin{array}{l}\text { Age } \\
\text { of } \\
\text { onset }\end{array}$ & $\begin{array}{l}\text { Duration } \\
\text { (years) }\end{array}$ & Family history & $\begin{array}{l}\text { Alcohol } \\
\text { response }\end{array}$ & Medications & $\begin{array}{l}\text { Head } \\
\text { tremor }\end{array}$ & $\begin{array}{l}\text { Kinetic } \\
\text { arm } \\
\text { tremor }\end{array}$ & $\begin{array}{l}\text { Rest } \\
\text { tremor }\end{array}$ & $\begin{array}{l}\text { Video- } \\
\text { stroboscopy }\end{array}$ & $\begin{array}{l}\text { Visible palatal or } \\
\text { pharyngeal muscle } \\
\text { tremor }\end{array}$ & $\begin{array}{l}\text { Response to } \\
1 \text { gm sodium } \\
\text { oxybate }\end{array}$ \\
\hline 1 & $\mathrm{~F}$ & 56 & 4 & No & Unaware & $\begin{array}{l}\text { Primidone (mild response, } \\
\text { side effects) }\end{array}$ & No & No & No & Yes & Yes & N/A \\
\hline 2 & $\mathrm{~F}$ & 71 & 3 & No & Yes & None & Slight & Slight & No & Yes & Not commented upon & N/A \\
\hline 3 & $\mathrm{~F}$ & 64 & 2 & Vocal tremor (Mother) & Unaware & None & Slight & No & No & No & Yes & N/A \\
\hline 4 & $\mathrm{~F}$ & 70 & 10 & No & Unaware & $\begin{array}{l}\text { Lorazepam (slight } \\
\text { improvement) }\end{array}$ & Slight & No & No & No & Yes & N/A \\
\hline 5 & $\mathrm{~F}$ & 69 & 2 & No & Unaware & Atenolol (No response) & Slight & No & No & Yes & Yes & N/A \\
\hline 6 & $\mathrm{~F}$ & 87 & 1 & No & Unaware & Lorazepam (No Response) & Slight & No & No & No & Yes & N/A \\
\hline 7 & $\mathrm{~F}$ & 54 & 15 & Parkinson & Yes & None & No & Slight & No & No & Yes & Mild improvement \\
\hline 8 & $\mathrm{~F}$ & 69 & 3 & $\begin{array}{l}\text { Action tremor (Mother), } \\
\text { Vocal tremor (Sister) }\end{array}$ & Yes & $\begin{array}{l}\text { Mirapex (No response); } \\
\text { Primidone (No Response) }\end{array}$ & No & Slight & No & Yes & Not Commented Upon & Mild improvement \\
\hline 9 & $\mathrm{~F}$ & 56 & 5 & Vocal tremor (Mother, Sister) & Yes & Propranolol (No Response) & No & No & No & Yes & Yes & Mild improvement \\
\hline 10 & $\mathrm{~F}$ & 64 & 6 & No & Unaware & Propranolol (No Response) & No & No & No & Yes & Yes & Mild improvement \\
\hline 11 & M & 72 & 15 & No & Yes & None & Slight & No & No & No & Yes & Mild improvement \\
\hline 12 & $\mathrm{~F}$ & 63 & 2 & Action tremor (Father) & Yes & Primidone (Unknown Response) & No & No & No & No & Yes & N/A \\
\hline 13 & $\mathrm{~F}$ & 66 & 3 & Vocal tremor (Mother) & Unaware & $\begin{array}{l}\text { Primidone (Mild improvement, } \\
\text { Yes side effects) }\end{array}$ & No & Slight & No & No & Yes & N/A \\
\hline 14 & $\mathrm{~F}$ & 45 & 20 & Action tremor (Father, Son) & Yes & $\begin{array}{l}\text { Primidone (Moderate } \\
\text { improvement) }\end{array}$ & Slight & No & Slight & No & Yes & N/A \\
\hline 15 & $\mathrm{~F}$ & 70 & 2 & No & Unaware & None & No & No & No & No & Yes & N/A \\
\hline 16 & $\mathrm{~F}$ & 81 & 3 & No & Yes & $\begin{array}{l}\text { Primidone (Moderate } \\
\text { improvement) }\end{array}$ & No & No & No & No & Yes & N/A \\
\hline 17 & M & 56 & 6 & $\begin{array}{l}\text { Tremor (Father, Paternal } \\
\text { Aunt/Uncle/Grandmother }\end{array}$ & Yes & $\begin{array}{l}\text { Propranolol (Mild } \\
\text { improvement) }\end{array}$ & No & No & No & Yes & Yes & Mild improvement \\
\hline 18 & $\mathrm{~F}$ & 65 & 9 & No & Yes & $\begin{array}{l}\text { Propranolol, Primidone } \\
\text { (Mild improvement) }\end{array}$ & Slight & Slight & No & Yes & Yes & Mild improvement \\
\hline 19 & $\mathrm{~F}$ & 45 & 2 & $\begin{array}{l}\text { Action tremor (Father), } \\
\text { Vocal tremor (Paternal Aunt) }\end{array}$ & Yes & $\begin{array}{l}\text { Propranolol (Moderate } \\
\text { improvement) }\end{array}$ & No & No & No & Yes & Yes & N/A \\
\hline
\end{tabular}


Table 2 Vocal tremor case series comparative analysis

\begin{tabular}{|c|c|c|c|c|c|c|c|c|}
\hline Study & Year & $\begin{array}{l}\text { No. of } \\
\text { cases }\end{array}$ & Mean age & $\begin{array}{l}\text { Mean duration of } \\
\text { symptoms (years) }\end{array}$ & $\begin{array}{l}\text { Female } \\
(\%)\end{array}$ & $\begin{array}{l}\text { Family } \\
\text { history (\%) }\end{array}$ & $\begin{array}{l}\text { Isolated vocal } \\
\text { tremor (\%) }\end{array}$ & $\begin{array}{l}\text { Alcohol } \\
\text { response (\%) }\end{array}$ \\
\hline Brown et al. [11] & 1963 & 31 & & & 55 & 52 & 19 & \\
\hline Koller et al. [12] & 1985 & 7 & 64 & 16 & 14 & 57 & 14 & \\
\hline Busenbark et al. [13] & 1996 & 9 & 73 & 32 & 89 & & & \\
\hline Hertegard et al. [14] & 2000 & 15 & 73 & & 87 & & & \\
\hline Warrick et al. [15] & 2000 & 10 & 64 & 12 & 80 & 20 & & 40 \\
\hline Adler et al. [16] & 2004 & 13 & 73 & & 85 & 38 & 54 & \\
\hline Bove et al. [17] & 2006 & 20 & 66 & 8 & 55 & 45 & & 45 \\
\hline Sulica and Louis [8] & 2010 & 34 & 70 & 7 & 93 & 38 & 56 & 27 \\
\hline Patel and Frucht & 2014 & 19 & 64 & 6 & 89 & 42 & 42 & 58 \\
\hline
\end{tabular}

Our case series supports the findings of more recent studies of voice tremor which suggest that voice tremor can occur in isolation or with limb tremor of little or no consequence. Sulica and Louis determined that $56 \%$ of patients in their voice tremor study had arm tremor within the range observed in similarly matched aged controls, as determined by the WHIGET scale [8]. Our retrospective review found a similar percentage of patients without clinically significant limb tremor through a qualitative assessment. In our series, the 8 patients with IVT and 11 patients with vocal tremor plus head/limb tremor showed similar characteristics of age, gender, and alcohol responsivity. The historical categorization of voice tremor as a secondary feature of ET thus likely contributes to the under-recognition of essential voice tremor in clinical practice. Further longitudinal studies are needed to determine if these IVT patients develop tremor elsewhere or better resemble classic ET patients over time.

At the same time, it is important to recognize that inclusion of IVT in groups of ET patients may not be helpful when investigating the etiology and pathogenesis of ET. Indeed, emerging understanding of the broad heterogeneity of ET, which IVT adds to, suggests that ET may be a family of disorders rather than a single entity. This has significant research implications for correctly identifying disease risk factors, prognostic markers, and future clinical trial design which may be specific to the "type" of ET studied [21].

Limitations of our retrospective review include the lack of electrophysiologic characterization of voice and limb tremor. Similarly, not all patients had videostroboscopic evaluation. Mild cases of adductor spasmodic dysphonia may be misdiagnosed as essential voice tremor. Without electromyographic evaluation of the vocal cords or limbs, subtle dystonic tremor which appears regular can mimic essential tremor on qualitative evaluation [22]. However, the similar age of onset, rates of familial tremor, lack of other dystonic features (phoneme-specific voice breaks, sensory geste antagoniste), and robust alcohol response in our cases compared with known ET characteristics all suggest that misdiagnosis in these cases was less likely. Further confounding this distinction between dystonia and ET is the possibility that involuntary movements like dystonia may co-occur in long-standing "pure" ET patients; raising the question as to whether such patients have two diseases or a secondary feature of a singular condition [23]. Indeed, patient 1 in Additional file 1: Video S1 has a slight head tilt during singing and a co-occuring cervical dystonia may not be excluded by exam alone.

\section{Conclusions}

This retrospective review adds to the growing understanding of essential voice tremor as part of the heterogeneous presentation of ET. Recognition of IVT occurring in the absence of "classic" ET features may aid in improving diagnosis and identifying new therapeutics for this functionally disabling and often medically refractory condition.

\section{Additional files}

\footnotetext{
Additional file 1: Videos S1 and S2. Isolated vocal tremor 1, Isolated vocal tremor 2, Isolated vocal tremor 3. Legend: Sustained vowel (A and E) phonation most reliably brings out the vocal tremor. Singing or changing pitch does not improve the tremor, unlike in cases of spasmodic dysphonia. The patients had a similar frequency tremor during normal spontaneous speech (not shown). Videostroboscopic examination of both patients performed by ENT consultant was consistent with vocal cord tremor rather than spasmodic dysphonia.

Additional file 2: Video S3. Legend: Patient 1 manifests a tremor of the pharyngeal musculature which can be easily observed by the examiner. Patient 2 displays a prominent tremor of the soft palate.

Laryngoscopy and videostroboscopic evaluations of patient 2 were more consistent with vocal tremor than spasmodic dysphonia.
}

Abbreviations

IVT: Isolated vocal tremor; ET: Essential tremor. 


\section{Competing interests}

The authors declare that they have no competing interests.

\section{Authors' contributions}

AP participated in study design and drafting the manuscript. SF conceived of the study, participated in its design and helped to revise the manuscript.

Both authors read and approved the final manuscript.

Received: 8 July 2014 Accepted: 18 January 2015

Published online: 02 March 2015

\section{References}

1. Louis ED. Essential tremor. Lancet Neurol. 2005;4(2):100-10.

2. Jimenez-Jimenez FJ, Alonso-Navarro H, Garcia-Martin E, Lorenzo-Betancor O, Pastor P, Agundez JA. Update on genetics of essential tremor. Acta Neurol Scand. 2013;128(6):359-71.

3. Louis ED, Ottman R. How familial is familial tremor? The genetic epidemiology of essential tremor. Neurology. 1996;46(5):1200-5.

4. Elble RJ. Diagnostic criteria for essential tremor and differential diagnosis Neurology. 2000;54(11 Suppl 4):S2-6.

5. Deuschl G, Bain P, Brin M. Consensus statement of the movement disorder society on tremor. Mov Disord. 1998;13 Suppl 3:2-23.

6. Findley $L$, Koller WC. Definitions and behavioral classifications. In: Findley $L J$ Koller W, editors. Handbook of tremor disorders. New York: Marcel Dekker; 1995. p. 1-5.

7. Jankovic J. Essential tremor: clinical characteristics. Neurology. 2000;54(11 Suppl 4):S21-5.

8. Sulica L, Louis ED. Clinical characteristics of essential voice tremor: a study of 34 cases. Laryngoscope. 2010;120(3):516-28.

9. Louis ED. When do essential tremor patients develop head tremor? Influences of age and duration and evidence of a biological clock Neuroepidemiology. 2013;41(2):110-5.

10. Romero JP, Benito-Leon J, Bermejo-Pareja F. The NEDICES study: recent advances in the understanding of the epidemiology of essential tremor. Tremor Other Hyperkinet Mov. 2012;2:tre-02-70-346-2. Epub 2012 Jun 15.

11. Brown JR, Simonson J. Organic voice tremor: a tremor of phonation. Neurology. 1963;13:520-5.

12. Koller W, Graner D, Mlcoch A. Essential voice tremor: treatment with propranolol. Neurology. 1985;35(1):106-8.

13. Busenbark K, Ramig L, Dromey C, Koller WC. Methazolamide for essential voice tremor. Neurology. 1996;47(5):1331-2.

14. Hertegard S, Granqvist S, Lindestad PA. Botulinum toxin injections for essential voice tremor. Ann Otol Rhinol Laryngol. 2000;109(2):204-9.

15. Warrick P, Dromey C, Irish JC, Durkin L, Pakiam A, Lang A. Botulinum toxin for essential tremor of the voice with multiple anatomical sites of tremor: a crossover design study of unilateral versus bilateral injection. Laryngoscope. 2000;110(8):1366-74.

16. Adler CH, Bansberg SF, Hentz JG, Ramiq LO, Buder EH, Witt K, et al. Botulinum toxin type A for treating voice tremor. Arch Neurol. 2004;61 (9):1416-20.

17. Bove M, Daamen N, Rosen C, Wang CC, Sulica L, Gartner-Schmidt J. Development and validation of the vocal tremor scoring system. Laryngoscope. 2006;116(9):1662-7.

18. Koller WC, Busenbark K, Miner K. The relationship of essential tremor to other movement disorders: report on 678 patients. Ann Neurol. 1994;35 (6):717-23.

19. Kralic JE, Criswell HE, Osterman JL, O'Buckley TK, Wilkie ME, Matthews DB, et al. Genetic essential tremor in gamma-aminobutyric acidA receptor alpha1 subunit knockout mice. J Clin Invest. 2005;115(3):774-9.

20. Frucht SJ, Houghton WC, Bordelon Y, Greene PE, Louis ED. A single-blind, open-label trial of sodium oxybate for myoclonus and essential tremor. Neurology. 2005;65(12):1967-9.
21. Louis ED. 'Essential tremor' or 'the essential tremors': is this one disease or a family of diseases? Neuroepidemiology. 2014;42:81-9.

22. Elble RJ. Defining dystonic tremor. Curr Neuropharmacol. 2013;11(1):48-52.

23. Louis ED, Hernandez N, Alcalay RN, Tirri DJ, Ottman R, Clark LN. Prevalence and features of unreported dystonia in a family study of "pure" essential tremor. Parkinsonism Relat Disord. 2013:19(3):359-62.

\section{Submit your next manuscript to BioMed Central and take full advantage of:}

- Convenient online submission

- Thorough peer review

- No space constraints or color figure charges

- Immediate publication on acceptance

- Inclusion in PubMed, CAS, Scopus and Google Scholar

- Research which is freely available for redistribution 